\title{
Formação de professores no Brasil: políticas para a modalidade a distância
}

\author{
Maria Emília Sardelich ${ }^{1}$
}

emilisar@hotmail.com

\section{Resumo}

Este trabalho tem por objetivo analisar as políticas para a formação de professores, na modalidade de Educação a Distância (EaD), a partir de 1996, última edição da Lei de Diretrizes e Bases da Educação (LDB), n. 9.394/1996. A pesquisa bibliográfica e documental destaca a formação dos professores no Brasil, no período compreendido entre 1996 a 2012. Enfatiza a formação de professores na $\mathrm{EaD}$ a partir de dois aspectos: como estratégia para expansão do ensino superior e modalidade de ensino. Examina a normatização da EaD no Brasil e os Programas para Formação de Docentes nessa modalidade, como o Programa Especial da Resolução CNE n. 2/1997, Pró-Licenciatura, Programa Universidade Aberta do Brasil e PARFOR a distância. Evidencia que o desenvolvimento da EaD no País está historicamente vinculado aos projetos governamentais para solucionar o crônico problema da carência de professores para a Educação Básica, configurando uma política de transferência de responsabilidade para o domínio da iniciativa privada.

Palavras-Chave: política educacional brasileira; formação de professores; educação a distância.

1 Doutora em Educação pela Universidade Federal da Bahia (UFBA). Professora da Universidade Federal da Paraíba (UFPB). 


\title{
Training teachers in Brazil: policies for distance learning
}

\begin{abstract}
This paper aims to analyze the Brazilian educational policy for training teachers from the last edition of the Law of Education n. 9394/1996, emphasizing the actions for the distance learning. The bibliographic research focuses aspects of the teacher training history in Brazil, since 1996 to 2011, current legislation and challenges to this training in the distance learning. The research deals with the EAD and the training of teachers from two hands: modality of learning and a key strategy for the expansion of higher education in the country. Examines the standardization of distance learning in Brazil and the programs for training of teachers in this modality, such as the Special Program of Resolution CNE n. 2/1997, Pro-Licenciatura, Open University of Brazil (UAB) Program and PARFOR at distance learning. Emphasizes that the development of EAD in the country is historically linked to government projects to solve the chronic problem of shortage of teachers for Basic Education.
\end{abstract}

Keywords: Brazilian educational policy; training teachers; distance learning.

\section{Introdução}

As primeiras experiências de Educação a Distância (EaD) no Brasil remontam a Fundação da Rádio Sociedade do Rio de Janeiro, em 1923, porém somente na década de 1970 se configura a Associação Brasileira de Tele-Educação (ABT). Esta organizava, desde 1969, os Seminários Brasileiros de Tele-Educação, atualmente denominados Seminários Brasileiros de Tecnologia Educacional, uma iniciativa pioneira para capacitar professores por correspondência (BARROS, 2003). O registro sistemático de dados sobre cursos superiores a distância se efetivou somente a partir dos anos 2000, sob a responsabilidade do Instituto Nacional de Estudos e Pesquisas Educacionais Anísio Teixeira (INEP), 
por meio do Censo da Educação Superior. Ao longo de toda a primeira década do século XXI, o INEP vem registrando o crescimento da EaD no País, que, no ano de 2012, de um total de 7.037 .688 matrículas no ensino superior, 1.113.850 optaram por cursos a distância, o que representa, aproximadamente, $15 \%$ do total das matrículas. Das matrículas na modalidade a distância, 449.966, aproximadamente $40 \%$, referem-se aos cursos de Licenciatura (BRASIL, 2013a).

O considerável aumento de número de matrículas em cursos de Licenciatura na modalidade a distância é resultado de uma política para a formação de professores iniciada a partir das reformas educacionais da década de 1990. Essas reformas se materializaram por meio de vários atos normativos: leis, decretos, resoluções, pareceres. Este artigo se inscreve na área da política educacional, compreendendo-a como campo de produção intelectual que estuda os problemas que cercam a Educação, neste caso a formação de professores na modalidade a distância, e as ações governamentais para equacioná-las (AZEVEDO, 2004). Tem por objetivo analisar as ações governamentais para formação de professores a partir da última edição da Lei de Diretrizes e Bases da Educação (LDB), n. 9.394/1996, enfatizando aquelas voltadas para a EaD, pois o artigo 80 da LDB possibilitou que o Poder Público incentivasse o desenvolvimento de programas de $\mathrm{EaD}$ em todos os níveis e modalidades de ensino. Delimitamos o estudo nesse recorte temporal pelo fato de o artigo 62 da LDB determinar a formação de docentes para atuar na Educação Básica em nível superior, em curso de Licenciatura, de graduação plena, extinguindo a categoria Licenciatura curta, instituída na década de 1970 devido à onda expansionista do sistema de ensino e à carência de professores habilitados. A pesquisa bibliográfica e documental apresenta parte da história da formação dos professores no Brasil, no período compreendido entre 1996 a 2012, destacando a legislação vigente e os atuais desafios para essa formação na modalidade a distância. Analisa a normatização da EaD no Brasil e os Programas para Formação de Docentes nessa modalidade, entre estes o Programa Especial de Formação Pedagógica, regulamentado pela Resolução CNE n. 2/1997; o Pró-Licenciatura; o Programa Universidade Aberta do Brasil (UAB) 
e o Plano Nacional de Formação dos Professores da Educação Básica (PARFOR) a distância.

\section{As reformas educacionais da década de 1990}

No Brasil, as reformas para a formação do professor, iniciadas na década de 1990, não estão isoladas do contexto internacional e se originam nas Conferências Mundiais da Educação para Todos, realizadas em Jomtien (1990) e Dakar (2000), entre outras indicações expressas em documentos expedidos pelos organismos internacionais como o Banco Mundial (BM), a Organização das Nações Unidas para a Educação, Ciência e Cultura (UNESCO), a Organização de Cooperação e Desenvolvimento Econômico (OCDE) e a Comissão Econômica para América Latina (CEPAL). É nesse contexto que, no Brasil, edita-se a terceira versão da LDB, em 1996, marco das reformas educacionais da década de 1990.

Azevedo (2004) destaca que nenhuma orientação dos organismos internacionais é transplantada mecanicamente para qualquer país. Essas orientações são recontextualizadas a depender das características históricas da sociedade a que se destinam. Consideramos que as reformas para a formação de professores no Brasil da década de 1990 foram recontextualizadas a partir do projeto político neoliberal. Compreendemos esse projeto como uma "estratégia de poder" que se articula no plano político e cultural para construir um novo senso comum a partir do qual as maiorias aceitam e defendem como próprias as receitas elaboradas pelas conservadoras tecnocracias neoliberais que privatizam o êxito e o fracasso social (GENTILI, 1994). A estratégia de poder neoliberal defende a tese de que toda forma de intervenção estatal atenta contra a liberdade individual e abre caminho para os regimes totalitários. No entendimento do projeto político neoliberal os sistemas educacionais enfrentariam, apenas, uma crise gerencial. A suposta crise de qualidade dos sistemas educacionais teria sua origem na improdutividade das práticas pedagógicas, na gestão administrativa dos estabelecimentos escolares e na inadequação da formação inicial 
de professores. É por essa razão que, no Brasil, ao longo da década de 1990, encontramos um conjunto de reformas para regular, reestruturar os sistemas de ensino flexibilizando sua oferta, reformular o perfil dos professores, implementar uma reforma curricular e, sobretudo construir o mercado educacional. Desse modo, os sistemas de ensino se subordinam às necessidades do mercado de trabalho, tendo como função social promover a empregabilidade, a capacidade flexível de adaptação individual às demandas do mercado de trabalho.

\section{A normatização da EAD}

Para Roesler e Vianney (2011), podemos identificar quatro períodos na normatização da EaD no Brasil: 1942-1995, 1996-2000, 2001-2006 e 2007-2011. Pelo recorte deste trabalho, focalizaremos a normatização da EaD a partir de 1993, pois consideramos que alguns atos governamentais desse período alicerçam o artigo 80 da LDB, editada três anos depois. Saraiva (1996) indica que a partir de 1993 o Ministério da Educação (MEC) deu início a uma série de medidas concretas para a formulação de uma política de EaD, assinando os protocolos de cooperação com o Ministério das Comunicações (MC) e com a Empresa Brasileira de Telecomunicações (Embratel), a fim de criar a infraestrutura tecnológica necessária para viabilizar essa modalidade de ensino. Também é relevante destacar o Acordo de Cooperação Técnica n. 4/1993, firmado entre o MEC e a Universidade de Brasília (UnB) para que esta coordenasse um Consórcio Interuniversitário "com a finalidade de dar suporte científico e técnico para a educação básica, utilizando os recursos da Educação Continuada e da Educação a Distância" (SARAIVA, 1996, p. 25, grifo nosso). Esse Acordo de Cooperação Técnica sinaliza, desde 1993, um acalentado projeto governamental para vincular o desenvolvimento da EaD no Brasil para a solução de um grave e crônico problema da política educacional do País: a carência de professores habilitados para todos os níveis de ensino.

Sobre o Consórcio Interuniversitário de Educação Continuada e a Distância (BRASILEAD), Guimarães (1996) destaca que este refletiu a recomendação feita pelos organismos internacionais sobre 
as dificuldades dos sistemas educacionais presenciais "responder às demandas dos sistemas produtivos, sociais, políticos, culturais e científico-tecnológicas reclamadas pela globalização das atividades do mundo contemporâneo" (GUIMARÃES, 1996, p. 29). A tentativa do Consórcio Interuniversitário BRASILEAD contou, na época, com o apoio de 54 instituições públicas. Um consórcio associa um grupo de instituições/empresas autônomas que têm operações comuns. Nesse caso, a criação do consórcio Interuniversitário pressupõe um mesmo Plano de Desenvolvimento Institucional (PDI) na modalidade a distância comum a todas as universidades que se associem. Apesar de associadas em torno de um mesmo PDI para modalidade a distância, cada Universidade manteria sua autonomia administrativa. Trata-se um uma experiência que procura otimizar os recursos das várias Universidades Federais (UFES) para não desperdiçar esforços com a mesma oferta de formação. A respeito da criação do BRASILEAD, Preti (1998) observa que o MEC reagiu tardiamente às iniciativas de criação de Redes de Educação a Distância. Diferentemente dos países que optaram, nas décadas de 1960 e 1970, pela criação de Universidades exclusivamente a distância, o legislativo brasileiro preferiu engavetar o Projeto de Lei n. 1.878, de 1974, que propunha uma Universidade Aberta cujo ensino fosse ministrado mediante processos de comunicação a distância (GOMES, 2009).

O Decreto no 1.237/1994 instituiu, no âmbito da administração federal, o Sistema Nacional de Educação à Distância (SINEAD) sob a coordenação do MEC. Em seu artigo $1^{\circ}$, esse Decreto define como objetivos do Sistema Nacional de Educação à Distância (SINEAD) facilitar a todo cidadão, por meio da educação aberta, continuada e a distância, o acesso ao conhecimento social e científico disponível na sociedade brasileira e de servir de apoio à consecução dos propósitos do Plano Decenal de Educação para Todos, aplicando os recursos das comunicações, telecomunicações e informática no sistema educacional brasileiro. Sobre a redação desse Decreto, destacamos a menção feita aos conceitos de educação aberta, continuada e a distância. Bates (1995) indica que a "educação aberta" é um objetivo geral de uma política educacional, a oportunidade de oferecer formação sem constrangimento social ou espaço temporal, e a "educação 
a distância" vem a ser um objetivo específico dessa política, ou seja, a EaD é um meio para concretizar a política de educação aberta. Sobre o conceito de "educação continuada", Gatti (2008) observa que o uso dessa expressão, seja em documentos ou nos estudos educacionais, não tem sentido preciso. O uso restrito dessa expressão se refere aos cursos formais realizados após a formação inicial, após a graduação, ou após o ingresso no exercício do magistério. $\mathrm{O}$ uso amplo abarca qualquer tipo de atividade que venha a contribuir para o desempenho profissional.

Na redação do artigo $1^{\circ}$ do Decreto n. 1.237/1994, podemos constatar que o SINEAD emerge como apoio à consecução dos propósitos do Plano Decenal de Educação para Todos, resultado dos acordos firmados pelo governo brasileiro na Conferência Mundial sobre Educação para Todos, de 1990, em Jomtien, na Tailândia, e não como um meio para concretizar uma política de Educação Aberta. O Plano Decenal de Educação para Todos, de 1993-2003, indicava metas para erradicação do analfabetismo e universalização do ensino fundamental, apontados pelos organismos internacionais como obstáculos para a modernização do País. O Plano estabeleceu muitas metas a serem alcançadas, das quais destacamos três:

[...] elevar a, no mínimo, $94 \%$ a cobertura da população em idade escolar; ampliar o atendimento de jovens e adultos, de modo a oferecer oportunidades de educação básica equivalente ao ensino fundamental para 3,7 milhões de analfabetos e 4,6 milhões de subescolarizados; promover a revisão crítica dos cursos de licenciatura e da escola normal, de forma a assegurar às instituições formadoras um novo padrão de qualidade, compatível com os requerimentos atuais da política de educação para todos. (BRASIL, 1994, p. 25)

Sem dúvida nenhuma, diante da magnitude numérica a ser superada, a política educacional daquele momento não poderia desconsiderar a EaD na tentativa de alcançar metas tão gigantescas. As políticas educacionais brasileiras da década de 1990 se conformam para superar a defasagem educativa do Brasil em relação a outros países e todo e qualquer recurso foi utilizado com essa finalidade. Apresentamos as metas do Plano Decenal de 1993-2003 a fim de exemplificar os fatores conjunturais que foram favoráveis para o novo impulso dado à EaD na década de 1990: expandir o acesso à escolarização e promover a revisão dos cursos de 
Licenciatura. Preti (1998) observa que a conjuntura econômica e política da década de 1990 identificou na EaD uma alternativa economicamente viável para os sistemas de ensino cumprirem sua tarefa de maneira rápida, atingindo um grande número de aprendizes, passando a ocupar uma posição instrumental estratégica para "contenção de gastos nas áreas de serviços educacionais e, no nível ideológico, traduz a crença de que o conhecimento está disponível a quem quiser" (PRETI, 1998, p. 23).

Sobre o SINEAD, Preti (1998) advertiu que um sistema nacional não seria um caminho adequado dada a dimensão geográfica do País e as dificuldades de supervisão in loco por parte do MEC. Por essa razão, recomendava que seria mais produtivo a implantação de um modelo dual, no qual as instituições educativas integrassem a modalidade a distância. Desse modo, as diferenças culturais, as distâncias e os problemas sociais poderiam ser atendidos por iniciativas locais e regionais. Com a criação da Secretaria de Educação a Distância (SEED), em 1996, os convênios anteriormente firmados para a instituição do SINEAD passaram a ser revistos em função da nova estrutura a ser organizada pela SEED e sua consequente normatização.

A edição da LDB, em 1996, legalizou a EaD no Brasil, em seu artigo 80. Os parágrafos desse artigo indicam a necessidade da União credenciar as Instituições de Ensino Superior (IES) especificamente para essa modalidade, e que normas para produção, controle e avaliação de programas de EaD, bem como a autorização para sua implementação, caberiam aos respectivos sistemas de ensino. Encontramos no parágrafo $4^{\circ}$, do artigo 32 a indicação da EaD para o Ensino Fundamental como complementação da aprendizagem ou em situações emergenciais. O inciso II do artigo 87 recomenda o uso da EaD para a inclusão educacional de jovens e adultos, e o inciso III para a capacitação de professores. Podemos constatar que, com o amparo legal da LDB, a EaD está vinculada à finalidade do SINEAD, apontada no Decreto n. 1.237/1994, de servir de apoio à consecução dos propósitos do Plano Decenal de Educação para Todos, daí a menção às situações emergenciais no Ensino Fundamental, a inclusão de jovens e adultos e, sobretudo, a capacitação de professores.

Lobo Neto (2003) observa que no período anterior à LDB, e 
consequentemente à regulamentação da $\mathrm{EaD}$, as propostas nessa modalidade de ensino eram submetidas à apreciação do então Conselho Federal de Educação (CFE), atual Conselho Nacional de Educação (CNE) e Conselhos Estaduais de Educação (CEE). Nesses Conselhos, as propostas de EaD recebiam pareceres de funcionamento a título precário, devido ao caráter excepcional dessas experiências. Em relação às políticas públicas para a EaD no Brasil, Belloni (2002) destaca que estas apresentam características recorrentes, pois são de caráter tecnocrático, autoritário e centralizador, favorecendo resultados medíocres enquanto que a iniciativa privada ganha espaço, constrói competência e obtém verbas públicas.

Em 1998, os Decretos n. 2.494 e n. 2.561 regulamentaram o artigo 80 da LDB. Esses Decretos foram revogados posteriormente, por isso destacamos a concepção de EaD indicada no Decreto n. 2.494 como forma de ensino que possibilita a autoaprendizagem, com a mediação de recursos didáticos sistematicamente organizados, apresentados em diferentes suportes de informação, utilizados isoladamente ou combinados, e veiculados pelos diversos meios de comunicação. Desse modo, há um entendimento de que a EaD abarque todos os cursos que não sejam integralmente presenciais. Ressaltamos o parágrafo $1^{\circ}$, do artigo 2 desse Decreto, que determina que a oferta de programas de mestrado e de doutorado na modalidade a distância será objeto de regulamentação específica. A respeito desse aspecto, perguntamo-nos sobre as razões desse Decreto, que considerava a EaD como forma de ensino que possibilita a autoaprendizagem, contraditoriamente regular para níveis de ensino em que a autoaprendizagem pode ser mais questionada, como no ensino Fundamental para jovens e adultos, no Ensino Médio, na educação profissional e na graduação. Quais seriam os motivos que levaram esse Decreto a permitir uma modalidade de ensino de autoaprendizagem para os níveis mais elementares da escolarização e exigir regulamentação específica justamente para os níveis de ensino em que a autoaprendizagem já deveria ter sido conquistada?

O Decreto n. 5.622, de 2005, revogou os Decretos n. 2.494 e n. 2.561, de 1998, além de modificar a definição anterior de EaD, que, de processo de autoaprendizagem, passou a ser considerada modalidade 
educacional na qual a mediação didático-pedagógica nos processos de ensino e aprendizagem ocorre com a utilização de meios e tecnologias de informação e comunicação, com estudantes e professores desenvolvendo atividades educativas em lugares ou tempos diversos. Na legislação brasileira, trata-se da única modalidade de ensino que não é designada pelo nível de ensino (Educação Infantil, Ensino Fundamental, Médio, Profissional, Superior), nem pelo público a que se destina (crianças, jovens e adultos), mas sim pelo seu modus operandi, que se baseia na centralidade das tecnologias, sem discutir o uso educacional delas e reduzindo-as a ferramentas dessa modalidade de educação (BARRETO, 2008).

O Decreto n. 5.622/2005 também indica a preocupação com a qualidade da EaD, sobretudo em aspectos relacionados ao credenciamento institucional, supervisão, acompanhamento e avaliação, visando a reprimir os abusos por parte das instituições com oferta desmesurada do número de vagas desvinculada da previsão de condições de atendimento aos alunos. Apesar de autorizar a criação de cursos de pós-graduação stricto sensu, esse Decreto manteve a exigência de atos anteriores para que as normas complementares desses cursos se mantivessem sob a responsabilidade da Coordenação de Aperfeiçoamento de Pessoal de Nível Superior (CAPES). Dois anos depois, o Decreto n. 5.622/2005 foi complementado pelo Decreto n. 6.303/2007, estabelecendo normas para o credenciamento de instituições para oferta nessa modalidade. Esses Decretos fundamentam a obrigatoriedade de momentos presenciais e a prevalência da avaliação presencial sobre os resultados obtidos em quaisquer outras formas de avaliação a distância.

Em 2007, temos a segunda versão dos Referenciais de Qualidade para Educação a Distância. A SEED havia apresentado uma primeira versão desses Referenciais em 2003. Esses Referenciais se circunscrevem no ordenamento legal da $\mathrm{EaD}$, porém não têm força de Lei. O documento indica que ele tem a finalidade de "subsidiar atos legais do poder público no que se referem aos processos específicos de regulação, supervisão e avaliação" da EaD, com "função indutora, não só em termos da própria concepção teórico-metodológica da educação a distância, mas também da organização de sistemas de EaD” (BRASIL, 2007, p. 2). 
Apesar de reconhecer a sua "função indutora", o documento afirma textualmente que "Não há um modelo único de educação à distância!" (BRASIL, 2007, p. 7). O documento insiste em indicar que os programas nessa modalidade podem apresentar diferentes desenhos e múltiplas combinações de linguagens e recursos educacionais e tecnológicos, pois é a natureza do curso e as condições dos participantes que devem definir as estratégias. Apesar desses esclarecimentos, os Referenciais impõem o modelo de EaD a ser seguido pelas IES, pois esses critérios acabam sendo incorporados nos Instrumentos de Avaliação para o reconhecimento e credenciamento de cursos. Um modelo de acordo com a nova ortodoxia oficial (HARGREAVES et al., 2002), decorrente de um movimento de padronização e centralização curricular focado no produto da ação educativa e num sistema de avaliação padronizado e centralizado.

Mill e Fidalgo (2012) apontam que os programas de EaD no Brasil têm apresentado um padrão de funcionamento a partir de dois grandes "modelos": central-polos e virtual. O modelo central-polos está estruturado a partir de uma organização central que concebe, produz e oferece o curso em parceria com polos de recepção e apoio presencial ao aluno. Esse modelo seria mais vantajoso do ponto de vista social, da democratização do conhecimento, pautado na interiorização dos grandes centros de produção do conhecimento e no desenvolvimento das regiões economicamente e culturalmente desfavorecidas, porém é um tipo de organização complexa e dispendiosa. O modelo virtual funciona em suportes virtuais sem apoio presencial significativo e não necessariamente complementado por outras mídias. Esse modelo é menos oneroso e mais flexível para a organização, porém exclui toda a parcela da população desprovida de acesso às tecnologias digitais e sem competência prévia no domínio dessas tecnologias. Embora esta seja uma desvantagem para a EaD, Mill e Fidalgo (2012) observam que o modelo virtual não implica necessariamente uma perversidade.

No ano de 2009, a Lei n. 12.056/2009, incluiu três parágrafos no artigo $62^{\circ}$ da LDB, esclarecendo que a formação inicial de profissionais de magistério desse preferência ao ensino presencial, subsidiariamente fazendo uso de recursos e tecnologias de educação a distância e que a 
formação continuada e a capacitação dos profissionais de magistério poderão utilizar recursos e tecnologias de educação a distância.

\section{Programas de formação de professores a distância}

Em seu artigo 62, a atual LDB determinou que a formação dos profissionais da Educação Básica far-se-á em nível superior em cursos de Licenciatura. O artigo 87, parágrafo $4^{\circ}$, da LDB estabeleceu que em um prazo de dez anos, a partir da publicação da Lei, somente seriam admitidos professores na Educação Básica habilitados em nível superior ou formados por treinamento em serviço. O artigo 63, inciso II, da mesma Lei também prevê programas de formação pedagógica para portadores de diplomas de educação superior que queiram se dedicar à Educação Básica. Como fato recorrente na História da Educação Brasileira - a exigência da Lei e a falta de licenciados para atuarem nos sistemas de ensino -, vários programas para a formação emergencial de professores têm sido lançados. Esses programas têm se sobreposto sem completar o seu próprio ciclo como políticas públicas. Gelinski e Seibel (2008) esclarecem que, usualmente, concebe-se o ciclo das políticas como o processo de formulação, implementação, acompanhamento e avaliação. Os programas para a formação de professores lançados desde 1997 se caracterizam pela sobreposição, falta de acompanhamento e avaliação. Entre estes, vamos destacar o Programa Especial de Formação Pedagógica da Resolução CNE n. 2/1997; o Pró-Licenciatura; o Programa UAB e o PARFOR a distância.

\subsection{Programa Especial de Formação Pedagógica de Docentes}

O Programa Especial de Formação Pedagógica de Docentes foi regulamentado por meio da Resolução CNE n. 2/1997. O artigo $7^{\circ}$ dessa Resolução permite que Universidades e IES que tenham cursos de Licenciatura reconhecidos e se articulem com escolas de Ensino Fundamental, Médio e Profissional nos quais a parte prática do programa se desenvolva possam oferecê-los sem autorização prévia. Em relação à carga horária do programa, o art. 4 indicou 540 horas, incluindo a parte 
teórica e prática, esta com duração mínima de 300 horas. Essa carga horária deve ser organizada em torno de três núcleos: contextual (para a compreensão do processo de ensino-aprendizagem referido à prática da escola); estrutural (para a compreensão dos conteúdos curriculares, sua organização sequencial, avaliação, integração e adequação ao processo de ensino-aprendizagem) integrador (para a compreensão do planejamento e reorganização do trabalho escolar). Sobre a prática, o artigo 5 determina que deva ser desenvolvida em instituições de ensino básico, envolvendo não apenas a preparação e o trabalho em sala de aula e sua avaliação, mas todas as atividades próprias da vida da escola, incluindo o planejamento pedagógico, administrativo e financeiro, as reuniões pedagógicas, os eventos com participação da comunidade escolar e a avaliação da aprendizagem, assim como de toda a realidade da escola. Diferentemente, a parte teórica, de acordo com o artigo 8, poderá ser oferecida utilizando metodologia semipresencial, na modalidade de ensino a distância, sem redução da carga horária prevista no artigo 4, sendo exigido o credenciamento prévio da instituição de ensino superior pelo $\mathrm{CNE}$, nos termos do art. 80 da LDB. Essa resolução faz menção à modalidade EaD, exigindo o credenciamento da IES para tanto.

Avaliamos que a Resolução CNE n. 2/1997 se fundamenta e realça a racionalidade técnica do modelo " $3+1$ " (VEIGA, 1996). Neste qualquer profissional cursa 540 horas de disciplinas pedagógicas; destas 300 horas em serviço, podem ser contabilizadas como estágio, o que lhe permite receber certificado e registro profissional equivalentes à Licenciatura com 240 horas de formação. Krahe e Wielewicki (2008) observam que as IES frequentemente externam um alinhamento com propostas fundamentadas na racionalidade prático-reflexiva de formação de professores, mas operam a partir da racionalidade técnico-instrumental. Reconhecemos essa mesma condição paradoxal no Programa Especial de Formação Pedagógica de Docentes. Avaliamos que esse Programa desacredita as exigências para a formação de professores não pelo fato de incluir a modalidade EaD quando, em 1997, ainda não contávamos com regulamentação pertinente à EaD nem lastro de experiências, mas sim por manter a lógica linear da aplicação direta da teoria na prática e 
também por favorecer a expansão desses programas em IES privadas, muitas sem cursos de Licenciatura reconhecidos, descomprometidas com a pesquisa, a investigação, a formação multidisciplinar. Ressaltamos que ações como o Programa Especial de Formação de Professores garantem a empregabilidade, ou seja, legaliza aqueles que atuam em escolas sem formação para tal e favorece a fabricação de números de docentes "formados", supostamente aptos ao exercício profissional. Esses programas oferecem um certificado e registro profissional para que esses profissionais se lancem no mercado educacional, porém o restante dependerá do indivíduo tornar-se, ou não, quem sabe, um bom professor, sendo que alguns triunfarão e outros estarão condenados ao fracasso (GENTILI, 1994). Parte-se de um pressuposto ingênuo que esse professor domina o conteúdo específico por ser bacharel em outra área, logo, uma carga horária mínima de conteúdo pedagógico lhe permite "dar aula" sem discutir a relação teoria/prática/teoria. Perpetua-se a concepção de que ensinar é muito fácil, basta repetir o que foi feito como aluno.

Azevedo (2004) adverte que as políticas públicas são definidas, implementadas, reformuladas ou desativadas com base na memória da sociedade ou do Estado em que têm curso. Consequentemente, essas políticas se constroem a partir das representações sociais, pois são estas que fornecem valores, normas e símbolos que estruturam as relações sociais. Avaliamos que esse programa é uma estratégia tão perversa quanto as Licenciaturas curtas da década de 1970, pois reforça o descaso com a educação básica e a desvalorização do professor, fruto do "nosso passado elitista, oligárquico, escravagista, [...] excludente, [...] de uma desigualdade atávica" (CURY, 2011, p. 2). Apesar do seu caráter emergencial, esse programa ainda está em vigor no início da segunda década do século XXI, revelando o problema estrutural da formação de professores no Brasil.

\subsection{Pró-Licenciatura}

A propalada carência de professores da educação básica também tentou ser contornada pelo Poder Público com o Programa PróLicenciatura. Em 2004, o MEC lançou o primeiro edital para o 
financiamento de cursos em nível superior na modalidade a distância desse Programa. Nesse edital, poderiam concorrer UFES organizadas em consórcios, com um projeto único que pudesse ser utilizado em todas as instituições participantes. Carvalho e Pimenta (2010) destacam que a exigência do MEC para a organização das UFES em consórcios procurava evitar a entrada maciça de instituições privadas internacionais que já haviam mostrado interesse em operar com a EaD no Brasil.

A documentação do Pró-Licenciatura indica como objetivo dele a melhoria da qualidade de ensino da educação básica, por meio da oferta de cursos de Licenciatura, na modalidade EaD, para formação inicial de professores em exercício na rede pública nos anos finais do Ensino Fundamental e ou Ensino Médio, nos sistemas estaduais e municipais de educação, sem licenciatura. O MEC se responsabilizou pela execução e gestão, por meio da Secretaria de Educação Básica (SEB) e da SEED; o FNDE pelo apoio financeiro; as IES públicas, comunitárias e confessionais por ofertarem os cursos; as Secretarias Estaduais e Municipais de Educação por aspectos administrativos do Programa.

Em 2005, a Resolução CD/FNDE n. 34 normatizou os critérios e procedimentos para o financiamento público do Pró-Licenciatura. Destacamos o artigo 2 com os critérios de elegibilidade das IES a serem financiadas desde que ofertassem cursos com duração igual ou maior que a mínima exigida para os cursos presenciais. Esse critério procurou rebater as críticas de aligeiramento na formação dos professore" (FREITAS, 2007).

A Resolução n. 49/2006, do FNDE, aprovou critérios e normas para concessão de bolsas de estudo e pesquisa. Apesar de ser uma Resolução do FNDE, órgão responsável pelo apoio financeiro, essa Resolução define a equipe docente envolvida nele, formada por professores nas funções de: pesquisadores, formadores, tutores e professores-cursistas. O Pró-Licenciatura foi lançado com a pretensão de ser um programa referência, porém sua própria regulamentação contraria seus objetivos ao prever uma equipe docente que, não necessariamente, estava vinculada às UFES participantes. Questionamos vários aspectos relacionados à equipe docente desse programa. Primeiramente, a divisão do trabalho 
fragmentado da autoria dos conteúdos, do desenho instrucional e da mediação pedagógica, baseada no modelo fordista/taylorista de produção industrial (BELLONI, 2002). Pesce (2009) advertiu que o modus operandi dos programas de formação docente não consideram a historicidade dos educadores, denominados, pelos programas, como professores-cursistas. Os participantes não são considerados como interlocutores, pois mesmo que sejam professores não podem sequer opinar sobre o conteúdo e não se reconhece sua autonomia. Pesce (2009) destaca que nesses programas os formadores e formandos interagem a partir de um script de autoria alheia.

Outro aspecto que questionamos são as denominações das funções docentes. Apesar dos termos tutor e tutoria serem amplamente empregados na EaD, considerarmos desnecessária tal nomenclatura para designar o trabalho docente. Dado que em todas as acepções a palavra tutor pertence ao campo semântico da proteção e a EaD é uma modalidade de ensino, o trabalho que se realiza para fomentar a aprendizagem não é um trabalho de proteção, mas sim de provocação e desafio. Qual seria a necessidade de se empregar o termo tutor e tutoria se o trabalho docente é um trabalho com identidade própria? Pesce (2009, p. 136) observa que os programas de formação docente em EaD se apoiam na "figura modelar de multiplicadores" para desonerar o Estado. Consideramos que as denominações de pesquisador, formador e tutor são empregadas para justificar salários diferenciados. Atribuise maior remuneração para o preparador de conteúdos, remuneração intermediária para o formador que supervisiona a equipe de tutoria e a mais baixa para o tutor, função responsável por mediar à relação do professor-cursista com os conteúdos e com todos os demais atores envolvidos no curso. A remuneração hierárquica das funções revela a concepção autoinstrucional do programa que atribui maior importância à produção dos conteúdos pelo pesquisador do que a intervenção da mediação pedagógica exercida pela função tutor.

Também destacamos os requisitos para a função tutor, pois estes contrariam o artigo 66 da LDB, ao determinar que a preparação para o exercício do magistério superior far-se-á em nível de pós-graduação, 
prioritariamente em programas de mestrado e doutorado. O PróLicenciatura não só aceitou tutores com formação no mesmo nível do curso ofertado como admitiu com nível inferior, médio, onde houvesse carência de tutores com formação em nível superior. Se esse Programa pretendia ser uma referência por que não desenvolveu estratégias para garantir uma equipe docente qualificada de acordo com os critérios do próprio Instrumento de Avaliação do INEP para os cursos do Ensino Superior?

Avaliamos que a modalidade EaD do Pró-Licenciatura foi incentivada para permitir que os professores matriculados não abandonassem a sala de aula, contrariando o inciso II, do artigo 67 da LDB, que prescreve a valorização dos profissionais mediante aperfeiçoamento profissional continuado, inclusive com licenciamento periódico remunerado para esse fim. O anexo III da Resolução CD/FNDE n. 34/2005 apresentou a Proposta Conceitual e Metodológica do Pró-Licenciatura, indicando "A escola que queremos" e "O professor que queremos". A política expressa pelo poder público nesse programa contraria a descrição da escola e professor que ele afirma querer. Como já indicamos, ele contraria a LDB, vale-se do trabalho de professores da escola pública em dupla jornada e remunera por meio de um incentivo financeiro abaixo do piso salarial, revelando "dissonância cognitiva". Schaff (1993) denomina de "dissonância cognitiva" um mecanismo que torna a nossa mente impermeável às novas verdades, que reflete o conflito entre a ideologia que se defende e os fatos que a refutam. Desse modo, as ações governamentais expressas nesse tipo de programa continuam utilizando os mesmos procedimentos recorrentes que já foram identificados como improcedentes. O Pró-Licenciatura não lançou novos editais e em abril de 2009 foi comunicado seu fim por meio da migração de seus cursos para o Programa UAB.

Analisando os dados do Censo de Educação Superior de 2012 podemos constatar que, apesar de todos os esforços do Programa PróLicenciatura, entre os anos de 2004 e 2007, o crescimento de matrículas na modalidade a distância nas IES Públicas é muito menor do que nas IES Privadas. Nessa tabela, incluímos na categoria IES Pública todas as matrículas das categorias administrativas: federal, estadual e municipal. 
TABELA 1 - MATRÍCULAS EAD

\begin{tabular}{c|c|c|c|c}
\hline Ano & $\begin{array}{c}\text { Total Matrículas } \\
\text { Ead }\end{array}$ & $\begin{array}{c}\text { Total } \\
\text { Matrículas } \\
\text { EaD } \\
\text { Licenciaturas }\end{array}$ & $\begin{array}{c}\text { Total } \\
\text { Matrículas EaD } \\
\text { Licenciaturas } \\
\text { IES Públicas }\end{array}$ & $\begin{array}{c}\text { Total } \\
\text { Matrículas EaD } \\
\text { Licenciaturas } \\
\text { IES Privadas }\end{array}$ \\
\hline 2004 & 59.611 & 51.459 & 35.989 & 15.470 \\
2005 & 114.642 & 78.402 & 43.430 & 34.972 \\
2006 & 207.206 & 149.808 & 37.746 & 112.062 \\
2007 & 369.766 & 215.728 & 47.889 & 167.839 \\
\hline
\end{tabular}

Fonte: BRASIL, 2013a.

Como podemos constatar na TAB. 1, no ano de 2006, após a regulamentação da EaD, via Decreto n. 5.622/2005, o número de matrículas nos cursos de Licenciatura EaD nas IES públicas diminui em, aproximadamente $1 \%$, enquanto que nas IES privadas cresce, aproximadamente $220 \%$ em relação ao ano de 2005. Também podemos observar como, entre os anos de 2004 e 2007, a participação das IES públicas e privadas se inverte, proporcionalmente, na porcentagem de matrículas nos cursos de Licenciatura na modalidade a distância. No ano de 2004, das 51.459 matrículas nos cursos de Licenciatura modalidade a distância, 35.989 estavam alocadas em IES públicas, representando aproximadamente $70 \%$ do total de matrículas, e 30 \% (15.470) em IES privadas. No ano de 2005, a participação das IES públicas no total de matrículas nas Licenciaturas a distância foi de, aproximadamente 55 \% e 45\% das IES privadas. Em 2006, a proporção das IES públicas cai para, aproximadamente $25 \%$ e das IES privadas eleva-se para $75 \%$. No ano de 2007 , as IES públicas contavam com 47.889 matrículas nas Licenciaturas EaD, perfazendo, aproximadamente $22 \%$ do total das matrículas e as IES privadas abarcavam 167.839 matrículas, aproximadamente 78 \% do total de matrículas na modalidade a distância (215.728). Esses dados indicam uma política de transferência de responsabilidade para o domínio da iniciativa privada.

\subsection{Programa UAB}

Já indicamos que, desde 1993, o MEC alimenta a concepção de um Consórcio Interuniversitário para criar um sistema de EaD voltado 
para a formação de professores da educação básica. O Acordo de Cooperação Técnica n. 4/1993, firmado entre o MEC e a Universidade de Brasília (UnB), colocou a UnB na dianteira desse processo. Em 1999, retomou-se essa concepção Consórcio Interuniversitário com a criação da Universidade Virtual Pública do Brasil (UniRede), sob o lema de "dar início a uma luta por uma política de Estado visando a democratização do acesso ao ensino superior público, gratuito e de qualidade e o processo colaborativo na produção de materiais didáticos e na oferta nacional de cursos de graduação e pós-graduação" (LEITE, [20--], n.p.)

Em outubro de 2000, a UniRede lançou um edital de oferta do curso de Especialização lato sensu de formação em EaD, promovido por 10 das 62 universidades interligadas. O consórcio adotou critérios de reserva de vagas e cobrança de taxas para seus cursos, contrariando sua finalidade inicial de promover a democratização do Ensino Superior. Batista (2002) destaca que o processo de formação da UniRede foi controverso, pois, apesar de formado por instituições públicas, não constituiu garantia de ensino público e gratuito, refletindo o jogo de interesses que perpassa a universidade pública brasileira abalada em sua autonomia e constrangida por restrições financeiras, transformando "o espaço público em domínio no qual prosperam interesses privados" (BATISTA, 2002, n.p.). O Consórcio UniRede abriu uma brecha para que as instituições públicas admitissem a implantação de ensino pago o que gerou uma grande expectativa dos investidores privados interessados no controle do promissor mercado educacional na modalidade a distância. Leite ([20-], n.p.) observa que o ponto principal da UniRede foi "construir uma rede pública centrada, principalmente na formação de professores da rede pública de ensino", porém esse objetivo não foi conquistado e esse consórcio suplantado pela criação de um novo consórcio denominado Programa Universidade Aberta do Brasil (UAB).

O Decreto n. 5.800/2006 instituiu a UAB para "o desenvolvimento da modalidade de educação a distância, com a finalidade de expandir e interiorizar a oferta de cursos e programas de educação superior no País" (BRASIL, 2012). Com a extinção da SEED, em 2011, o sistema UAB passou a ser gerido pela CAPES. Com a Lei n. 11.502/2007, a política 
para formação de professores, formulada até então pelo MEC, ganhou o reforço da CAPES. O artigo 2 dessa Lei destaca que a EaD deve ser privilegiada para a formação continuada enquanto que a formação inicial dá preferência pela modalidade presencial. Por essa razão, a CAPES criou duas novas diretorias, de EB Presencial (DEB) e de EB a Distância (DED), atualmente responsável pelo sistema UAB. Barreto (2010) observa que a transferência de responsabilidade da UAB para CAPES conferiu "uma espécie de selo de qualidade" ao programa, devido à experiência acumulada da CAPES na área de avaliação da pós-graduação. Apesar desse suposto selo de qualidade da CAPES, a UAB permanece, até o momento, "sem projeto pedagógico explícito" fundamentando-se na centralidade tecnológica (BARRETO, 2010, p. 39).

Os recursos para o financiamento da UAB estão previstos no Decreto n. 11.273/2006, na Lei n. 11.502/2007 e nas Resoluções CD/ FNDE n. 26/2009 e n. 8/2010. Encontramos, no Programa UAB, as mesmas fragilidades já apontadas no Pró-Licenciatura, pois o corpo docente da UAB também não é estável. Nos editais de seleção para tutores, encontramos os requisitos de possuir graduação na área ou áreas afins; estar efetivo no exercício do magistério da rede pública de ensino ou vinculado a um programa de pós-graduação; ter formação em nível superior e experiência mínima de um ano magistério do ensino básico ou superior, ou pós-graduação ou estar vinculados à pós-graduação stricto sensu. A pós-graduação não é exigência e está precedida pela conjunção ou, que indica alternância ou exclusão. Podemos constatar que a precariedade do trabalho docente também está explícita no Programa $\mathrm{UAB}$, revelando um modelo refém do receituário de organismos multilaterais em um "país campeão mundial de desigualdades, [que] deixou de cumprir funções estruturantes essenciais, entre elas a de garantir a manutenção, a expansão e a qualidade de sua universidade pública" (SGUISSARDI, 2005, p. 216).

Czerny et al. (2011) indicam o alcance das ações da UAB confrontando dados da CAPES sobre o programa com dados das Universidades envolvidas nele. Esses autores constataram distorções nas informações da CAPES em relação ao número de cursos que são sempre maiores 
que os indicados pelas próprias Universidades que os oferecem. Apesar do comprometimento das universidades públicas com a política para a formação de professores, os dados demonstram "que as demandas prioritárias tanto em termos regionais como na área de conhecimento não tem se efetivado" (CZERNY et al., 2011, p. 8).

A seguir apresentamos alguns dados do Censo da Educação Superior, referentes aos anos de 2006 e 2008.

TABELA 2 - MATRÍCULAS EAD

\begin{tabular}{c|c|c|c|c}
\hline Ano & $\begin{array}{c}\text { Total Matrículas } \\
\text { Ead }\end{array}$ & $\begin{array}{c}\text { Total } \\
\text { Matrículas } \\
\text { EaD } \\
\text { Licenciaturas }\end{array}$ & $\begin{array}{c}\text { Total } \\
\text { Matrículas EaD } \\
\text { Licenciaturas } \\
\text { IES Públicas }\end{array}$ & $\begin{array}{c}\text { Total } \\
\text { Matrículas EaD } \\
\text { Licenciaturas } \\
\text { IES Privadas }\end{array}$ \\
\hline 2006 & 207.206 & 149.808 & 37.746 & 112.062 \\
2007 & 369.766 & 215.728 & 47.889 & 167.839 \\
2008 & 727.961 & 341.118 & 101.492 & 239.626 \\
\hline
\end{tabular}

Fonte: BRASIL, 2013a.

A partir dos dados apresentados podemos constatar que, entre os anos de 2006 -criação da UAB por meio do Decreto n. 5.800 - e 2007, temos um significativo incremento de matrículas nas IES Públicas de, aproximadamente, 27\%. Entre os anos de 2007 e 2008, o incremento ascende a, aproximadamente, $112 \%$. Porém, se compararmos esses dados à proporção que cabe ao número de matrículas nas IES públicas (101. 492) com o total de matrículas nas Licenciaturas a distância (341.118), podemos constatar que, apesar do aumento no número de matrículas, a participação das IES públicas se mantém em, aproximadamente, 30\% do total de matrículas, enquanto que as IES privadas dispunham de, aproximadamente, $70 \%$ (239.626).

\subsection{PARFOR a distância}

Em 2009, o Decreto n. 6.755 instituiu a Política Nacional de Formação de Profissionais do Magistério da educação básica. Esse Decreto persiste nos recorrentes temas de outros atos normativos já apresentados, como 
a garantia dos padrões mínimos de qualidade dos cursos de formação de professores e sua relação direta com a qualidade da educação básica. Destacamos que, de acordo com dados do "Atlas Eletrônico Sobre Professores" (ORGANIZAÇÃO, 2012), entre os anos de 2005 e 2008, a relação quantitativa entre o número de Alunos por Docente (RAD) no Brasil havia aumentado de 21 para 23. O documento esclarece que o indicador RAD reflete a capacidade humana de um sistema educativo e adverte que muitos países conseguem melhorar tal indicador contratando professores inadequadamente preparados e precarizando as condições de trabalho com baixos salários para reduzir despesas. Essas estratégias têm sido utilizadas no Brasil e se refletiu no aumento da RAD entre os anos de 2005 e 2008, levando o poder público a lançar mais um programa emergencial em 2009.

A documentação referente ao Plano Nacional de Formação dos Professores da Educação Básica (PARFOR) indica que este é resultado de um conjunto de ações do MEC em colaboração com as Secretarias de Educação dos estados, municípios e Instituições Públicas de Ensino Superior (IPES) do País. A participação da CAPES se faz por meio da DEB e da DED, com o apoio das secretarias do MEC. A Resolução CNE/ CP n. 1, de 2009, estabelece diretrizes operacionais para a implantação do Programa Emergencial de Segunda Licenciatura para professores em exercício na educação básica. Dessa resolução, destacamos que o artigo 4 determina a organização curricular dos cursos articulando duas dimensões: a formação pedagógica e a específica. O parágrafo único determina que as IPES devem propor um projeto pedagógico de curso compatível com o projeto pedagógico institucional, analogamente ao que determina a Resolução CNE n. 2/1997. Esse parágrafo indica uma ambiguidade, pois as IPES devem compatibilizar o projeto institucional com a organização curricular proposta na Resolução CNE n. 2/1997, além de ter esse Projeto aprovado em seus órgãos colegiados próprios. A diferença entre os cursos do PARFOR e o Programa Especial da Resolução CNE n. 2/1997 se encontra no artigo 5 da Resolução CNE/CP n. 1/2009, pois a carga horária para os cursos do PARFOR varia entre um mínimo de 800 horas quando a segunda licenciatura pertencer à mesma área do curso de origem, e 1.200 horas quando o curso pertencer a uma área 
diferente da formação inicial do professor, não ultrapassando o máximo de 1.400 horas. Nesse ponto pode-se constatar outra dubiedade, pois as IPES devem prever Projetos diferenciados para professores originários da mesma área do curso e áreas diferentes, o que demanda um currículo personalizado em um programa de formação massiva.

O MEC desenvolveu um Sistema Informatizado de Gestão da Formação Nacional de Professores da Educação Básica, denominado "Plataforma Freire". O sistema permite a gestão do programa, desde a etapa de pré-inscrição ao acompanhamento dos cursos. Às Secretarias Estaduais e Municipais cabem organizar a demanda, segundo suas necessidades. O professor faz sua pré-inscrição por meio da "Plataforma Freire", e as secretarias validam a inscrição do professor de acordo com suas necessidades. O documento-síntese do PARFOR indica uma demanda em torno a 700 mil professores (BRASIL, 2009). Os números apontados nesse documento foram retirados do Censo Escolar (Educacenso) de 2007. Os dados da demanda de formação inicial de professores em exercício são referentes à função docente e não ao professor. A definição de função docente admite que um mesmo professor possa ser contabilizado mais de uma vez no exercício de suas atribuições em escolas de diferente dependência administrativa ou níveis e modalidades de ensino. Desse modo, uma previsão baseada em função docente superestima a demanda por formação inicial.

A CAPES (BRASIL, 2013b) divulga, em seu website, dados muito genéricos em relação ao andamento e acompanhamento das atividades do PARFOR. Segundo dados do website da CAPES, o PARFOR já teria implantado, até 2012, "1920 turmas" nas quais 54.000 professores da educação básica estariam frequentando os cursos em "turmas especiais do PARFOR” distribuídas em 397 municípios do País. A CAPES não divulga dados específicos sobre número de egressos de cada curso ofertado por IES, nem diferencia a modalidade presencial e a distância nesses dados genéricos. Tampouco indica se as matrículas nas turmas especiais do PARFOR estão contabilizadas no Censo de Educação Superior.

Apresentamos alguns dados do Censo da Educação Superior entre os anos de 2008 e 2010. 
TABELA 3 - MATRÍCULAS EAD

\begin{tabular}{c|c|c|c|c}
\hline Ano & $\begin{array}{c}\text { Total Matrículas } \\
\text { Ead }\end{array}$ & $\begin{array}{c}\text { Total } \\
\text { Matrículas } \\
\text { EaD } \\
\text { Licenciaturas }\end{array}$ & $\begin{array}{c}\text { Total } \\
\text { Matrículas EaD } \\
\text { Licenciaturas } \\
\text { IES Públicas }\end{array}$ & $\begin{array}{c}\text { Total } \\
\text { Matrículas EaD } \\
\text { Licenciaturas } \\
\text { IES Privadas }\end{array}$ \\
\hline 2008 & 727.961 & 341.118 & 101.492 & 239.626 \\
2009 & 838.125 & 420.094 & 97.523 & 322.571 \\
2010 & 930.179 & 426.241 & 102.984 & 323.257 \\
2011 & 992.927 & 429.549 & 104.785 & 324.764 \\
2012 & 1.113 .850 & 449.966 & 108.820 & 341.146 \\
\hline
\end{tabular}

Fonte: BRASIL, 2013a.

Analisando os dados do Censo de Educação Superior 2012, podemos constatar que, entre os anos de 2008 e 2009, após a implantação do PARFOR, temos um incremento de matrículas nas Licenciaturas EaD nas IES públicas de 3\% e de 34\% nas IES privadas. Entre os anos de 2009 e 2010, as matrículas nas IES públicas se incrementam em torno de 1,8\% e 4\% nas IES privadas. Finalmente, entre os anos de 2011 e 2012, as IES públicas voltam a incrementar as matrículas nas Licenciaturas EaD em $4 \%$, enquanto que nas IES privadas as matriculas crescem em torno de $5 \%$. Comparando esses dados com a proporção de matrículas por categoria administrativa pública e privada, podemos contatar que a proporção de matrículas nas IES públicas em relação ao total de matrículas nos cursos de Licenciatura a distância se mantém em, aproximadamente, $25 \%$ e $75 \%$ nas IES privadas.

\section{Considerações finais}

A partir da análise da normatização da EaD, dos Programas de Formação Pedagógica a distância e dos dados do Censo da Educação Superior de 2012 apresentados, podemos concluir que a política adotada para a formação de professores na modalidade a distância é uma política de transferência de responsabilidade para o domínio da iniciativa privada. 
TABELA 4 - MATRÍCULAS EAD

\begin{tabular}{c|c|c|c|c}
\hline Ano & $\begin{array}{c}\text { Total Matrículas } \\
\text { Ead }\end{array}$ & $\begin{array}{c}\text { Total } \\
\text { Matrículas } \\
\text { EaD } \\
\text { Licenciaturas }\end{array}$ & $\begin{array}{c}\text { Total } \\
\text { Matrículas EaD } \\
\text { Licenciaturas } \\
\text { IES Públicas }\end{array}$ & $\begin{array}{c}\text { Total } \\
\text { Matrículas EaD } \\
\text { Licenciaturas } \\
\text { IES Privadas }\end{array}$ \\
\hline 2001 & 5.359 & 5.359 & 5.359 & - \\
2002 & 40.714 & 38.811 & 34.322 & 4.489 \\
2003 & 49.911 & 47.191 & 39.804 & 7.387 \\
2004 & 59.611 & 51.459 & 35.989 & 15.470 \\
2005 & 114.642 & 78.402 & 43.430 & 34.972 \\
2006 & 207.206 & 149.808 & 37.746 & 112.062 \\
2007 & 369.766 & 215.728 & 47.889 & 167.839 \\
2008 & 727.961 & 341.118 & 101.492 & 239.626 \\
2009 & 838.125 & 420.094 & 97.523 & 322.571 \\
2010 & 930.179 & 426.241 & 102.984 & 323.257 \\
2011 & 992.927 & 429.549 & 104.785 & 324.764 \\
2012 & 1.113 .850 & 449.966 & 108.820 & 341.146 \\
\hline
\end{tabular}

Fonte: BRASIL, 2013a.

Os dados do Censo da Educação Superior de 2012, apresentados na TAB. 4, indicam como as IES privadas vêm ganhando, ano a ano, maior proporcionalidade nas matrículas dos cursos de Licenciatura a distância. Em 2001, as IES privadas abarcavam, apenas 11\% do total de matrículas nas Licenciaturas a distância e alcançaram 75\% em 2012. No âmbito das IES privadas, as matrículas predominam em instituições ligadas a grandes grupos financeiros, de capital aberto em Bolsa de Valores, que divulgaram para os seus investidores um lucro bruto em torno de 80\% na EaD, no segundo trimestre de 2012 (EDUCAÇÃO, 2012). Essas instituições têm seus cursos voltados para o público das classes B e C, e indicam que os fatores responsáveis pela alta lucratividade da EaD se devem ao uso da tecnologia e ao grande número de alunos atendidos. Esses fatores também estão diretamente relacionados com a precarização do trabalho docente (LAPA; PRETTO, 2010) na EaD.

Diante do desafio de aumentar o contingente de professores necessários para atender os sistemas de ensino, a política educacional para a formação do professor na modalidade a distância, que se conforma desde a década de 1990, é uma política de transferência de 
responsabilidade para o domínio da iniciativa privada. Do modo como vem sendo implementada, trata-se de uma política de desoneração do serviço público, desvalorização profissional com a precarização das condições de trabalho e enfraquecimento da formação, o que continuará sem atrair talentos para a docência na educação básica. 


\section{Referências}

AZEVEDO, J. M. L. de. A educação como política pública. 3. ed. Campinas, SP: Autores Associados, 2004.

BARRETO, R. G. As tecnologias na política nacional de professores a distância. Educação $\mathcal{E}$ Sociedade. Campinas, v. 29, n. 104, p. 891-917, out., 2008.

BARRETO, R. G. Configuração da política nacional de formação de professores a distância. Em Aberto, Brasília, v. 23, n. 84, p. 33-45, nov. 2010.

BARROS, D. M. V. Educação a Distância e o Universo do Trabalho. Bauru: EDUSC, 2003.

BATES, A. W. T. Technology, open learning and distance education. London: Routledge, 1995.

BATISTA, W. B. Educação a distância e o refinamento da exclusão social. Revista Conect@, n. 4, fev. 2002. Disponível em: <http:/ / www. revistaconecta.com/conectados/wagner_refinamento.htm>. Acesso em: 29 abr. 2012.

BELLONI, M. L. Ensaio sobre a educação a distância no Brasil. Educação E Sociedade, Campinas, SP, c. 23, n. 78, p.117-142. abr. 2002.

BRASIL. Ministério da Educação e do Desporto. Plano Decenal de Educação para Todos. Brasília, MEC, 1994.

BRASIL. Ministério da Educação. Secretaria de Educação a Distância. Referências de qualidade para a educação superior a distância. Brasília: SEED/MEC, 2007. 
BRASIL. Ministério da Educação. Coordenação de Aperfeiçoamento de Pessoal de Nível Superior. Diretoria de Educação Básica Presencial. Plano Nacional de Formação de Professores da Educação Básica: Documento Sintese. Brasília: DEB/CAPES, 2009.

BRASIL. Coordenação de Aperfeiçoamento de Pessoal de Nível Superior. 2012. Universidade Aberta do Brasil. Disponível em: <http:/ / www.uab.capes.gov.br/index.php>. Acesso em: 30 abr. 2012.

BRASIL. Ministério da Educação. Instituto Nacional de Estudos e Pesquisas Educacionais Anísio Teixeira. Censo da Educação Superior de 2012. Brasília, D. F.: Ministério da Educação/Inep, $2013 a$.

BRASIL. Coordenação de Aperfeiçoamento de Pessoal de Nível Superior. 2013b. Plano Nacional de Formação de Professores da Educação Básica - PARFOR. Disponível em: <http:/ / www.capes.gov. br/educacao-basica/parfor>. Acesso em: Acesso em: 30 out. 2013.

CARVALHO, A. B. G.; PIMENTA, S. de A. Políticas públicas de formação de professores da Educação Básica a Distância: o contexto do Pró-Licenciatura. Práxis Educacional, Vitória da Conquista, BA, v. 6, n. 9, p. 101-123, jul./dez. 2010.

CURY, C. R. J. Plano Nacional de Educação: questões desafiadoras e embates emblemáticos. In: SEMINÁRIO DE EDUCAÇÃO BRASILEIRA, 3., 28 de fevereiro, 01 e 02 março de 2011. Anais... Universidade Estadual de Campinas (UNICAMP). Campinas: Centro de Estudos Educação e Sociedade, 2011. Disponível em: <http:/ / www.cedes.unicamp.br/ seminario3/carlos_cury.pdf>. Acesso em: 19 out. 2012.

CZERNY, R. Z. et al. Política de formação de professores no Brasil: alcance das ações por meio da educação a distância. Novas Tecnologias na Educação, Porto Alegre, v. 9, n. 2, p. 35-51, dez, 2011. 
EDUCAÇÃO a distância dá margem de lucro bruto de até $82 \%$ às grandes instituições. Revista Ache seu curso, 21 ago. 2012. Disponível em: <http:/ / www.acheseucurso.com.br/margem-de-lucro-em-eadchega-a-82-por-cento.aspx>.

FREITAS, H. C. L. de. A nova política de formação de professores: a prioridade postergada. Educação \& Sociedade, Campinas, v. 28, n. 100 Especial, p. 1203-1230, out. 2007.

GATTI, B. A. Análise das políticas públicas para formação continuada no Brasil, na última década. Revista Brasileira de Educação, Rio de Janeiro, v. 13 n. 37, p. 57-186, jan./abr. 2008.

GELINSKI,C. R. O. G.; SEIBEL, E. J. Formulação de políticas públicas: questões metodológicas relevantes. Revista de Ciências Humanas, Florianópolis, EDUFSC, v. 42, n. 1 e 2, p. 227-240, abr./out. 2008.

GENTILI, P. Neoliberalismo e educação: manual do usuário. In: SILVA, T. T. da; GENTILI, P. G. (Org.). Escola S.A. Brasília: CNTE, 1994. p. 9-49.

GOMES, C. A. da Costa. A legislação que trata da EAD. In: LITTO, F.; FORMIGA, M. M. M. (orgs). Educação a distância: o estado da arte. São Paulo: Pearson Education do Brasil, 2009. p. 27-43.

GUIMARÃES, P. V. A contribuição do Consórcio Interuniversitário de Educação Continuada e a Distância - BRASILEAD - para o desenvolvimento da educação nacional. Em Aberto, Brasília, ano 16, n.70, p. 32-51,abr./jun. 1996.

HARGREAVES, A. et al. Aprendendo a mudar: o ensino para além dos conteúdos e da padronização. Porto Alegre: Artmed, 2002.

KRAHE, E. D.; WIELEWICKI, H. G. Formação docente, pedagogia universitária e mudanças de racionalidade: contribuições ao debate 
sobre políticas educativas. In: ENCONTRO INTERNACIONAL DE PESQUISADORES DE POLÍTICAS EDUCATIVAS, 3. 2008. Anais... Porto Alegre: UFRGS/FACED/Núcleo de Política e Gestão da Educação, p. 133-138, 2008.

LAPA, A. PRETTO, N. de L. Educação a distância e precarização do trabalho docente. Em Aberto, Brasília, v. 23, n. 84, p. 79-97, nov. 2010.

LEITE, S. Histórico da UniRede. In: UNIREDE. Website da Universidade Virtual Pública do Brasil, [20--]. Disponível em: <http://www.aunirede.org.br/portal/index.php?option=com_ content\&view=article\&id=43\&Itemid=27>. Acesso em: 29 abr. 2012.

LOBO NETO, F. J. da S. Regulamentação da educação a distância: caminhos e descaminhos. In: SILVA, M. Educação on-line: teorias, prática, legislação, formação corporativa. 2. ed. São Paulo: Loyola, 2003. p. 43-62.

MILL, D.; FIDALGO, F. O teletrabalho como categoria de análise da docência virtual: reflexões sobre o trabalho pedagógico a distância. In: FIDALGO, F. et al. (Orgs.). Educação a distância: tão longe, tão perto. Belo Horizonte: CEAD/UFMG, 2012. p. 53-87.

PESCE, L. O educador em foco: um olhar sobre as políticas de formação docente na modalidade de educação a distância. In: FELDMANN, M. G. (Org.) Formação de professores e escola na contemporaneidade. São Paulo: SENAC, 2009. p. 32-53.

PRETI, O. Educação a distância e globalização: desafios e tendências. Revista Brasileira de Estudos Pedagógicos, Brasília, v. 79, n. 191, p. 19-30, jan./abr. 1998.

ROESLER, J.; VIANNEY, J. Brasil. In: Leyes, Normas y Reglamentos que Regulan la Educación Superior a Distancia y en Línea en América Latina y 
el Caribe. Loja, Ecuador: Editorial de la Universidad Tecnica Particular de Loja, 2011. p. 43-65.

SARAIVA, T. Educação a distância no Brasil: lições da história. Em Aberto, Brasília, ano 16, n. 70, p. 19-38, abr./jun. 1996.

SCHAFF, A. A sociedade informática. São Paulo: UNESP/Editora Brasiliense, 1993.

SGUISSARDI, V. Universidade pública estatal: entre o público e o Privado/mercantil. Educação E Sociedade, Campinas, v. 26, n. 90, p. 191-222, jan./abr. 2005.

ORGANIZAÇÃO das Nações Unidas para a Educação, Ciência e Cultura. 2012. Atlas eletrônico sobre professores. Disponível em: <http:/ / www.uis.unesco.org/data/atlas-teachers/es>. Acesso em: 19 out. 2012.

VEIGA, I. P. A. A prática pedagógica do professor de didática. 3. ed. Campinas: Papirus, 1996.

Recebido: 20/10/2012 Aprovado: 13/12/2013 